DOI:http://dx.doi.org/10.18524/1810-4215.2019.32.182514

\title{
DISCOVERY OF MORE CHANGING LOOK EVENTS IN NGC 1566
}

\author{
V. L. Oknyansky ${ }^{1}$, H. Winkler ${ }^{2}$, S. S. Tsygankov ${ }^{3,4}$, V. M. Lipunov ${ }^{1}$, \\ E. S. Gorbovskoy ${ }^{1}$, F. van $\mathrm{Wyk}^{2}$, D. A. H. Buckley ${ }^{5}$, N. V. Tyurina ${ }^{1}$ \\ ${ }^{1}$ M. V. Lomonosov Moscow State University, Sternberg Astronomical Institute, \\ Moscow, Russia, oknyan@mail.ru \\ 2 Dept. Physics, University of Johannesburg, South Africa \\ ${ }^{3}$ Department of Physics and Astronomy, University of Turku, Finland \\ ${ }^{4}$ Space Research Institute of the Russian Academy of Sciences, Moscow, Russia \\ 5 The South African Astronomical Observatory, South Africa
}

\begin{abstract}
We summarize a study of optical, $\mathrm{UV}$ and X-ray light curves of the nearby changing look active galactic nucleus in the galaxy NGC 1566 obtained with the Neil Gehrels Swift Observatory and the MASTER Global Robotic Network over the period 2007-2019. We also report on optical spectroscopy using the South African Astronomical Observatory 1.9-m telescope between Aug. 2018 and Mar. 2019. A substantial increase in X-ray flux by 1.5 orders of magnitude was observed following the brightening in the UV and optical bands during the first half of 2018 year. After a maximum was reached at the beginning of July 2018, the fluxes in all bands decreased with some fluctuations. The most remarkable re-brightenings in of the light curve following the decline from the bright phase were observed at MJD range 58440-58494 and 58603-58654. The amplitude of the flux variability is strongest in the X-ray band and decreases with increasing wavelength. Low-resolution spectra (Aug 2018) reveal a dramatic strengthening of the broad emission as well as high-ionization [FeX]6374 lines. These lines were not detected so strongly in the past published spectra. The change in the type of the optical spectrum was accompanied by a significant change in the X-ray spectrum. For the last optical spectra (31 Nov. 2018 - 28 Mar. 2019) we see dramatic changes compared to 2 Aug 2018, accompanied by the fading of broad emission lines and high-ionization [FeX]6374 line. Effectively, two changing look (CL) cases were observed for this object: changing to Sy1.2 type and then returning to the low state as Sy 1.8-Sy1.9 type. Some possible explanations of the observed dramatic changes are discussed.
\end{abstract}

АНОТАЦІЯ. Ми наводимо i обговорюємо зведені оптичні, УФ та рентгенівські криві блиску найближчого активного галактичного ядра, який змінюе тип, в галактиці NGC 1566, які отримані за допомогою Обсерваторії Swift і Глобальної мережі автоматизованих телескопів MASTER за період 2007-2019 рр. Ми також представляємо результати оптичної спектроскопії, отриманої на 1.9-м телескопі Південно-Африканської Астрономічної обсерваторії в період з серпня 2018 року по березень 2019 року. Було виявлено значне збільшення, на 1,5 порядка, рентгенівського потоку, а також яскравості в УФ і оптичному діапазонах в першій половині 2018 р. Після досягнення максимуму на початку липня 2018 р., потоки на всіх довжинах хвиль зменшилися 3 деякими коливаннями. Найбільш помітні повторні спалахи в кривій блиску після максимуму спостерігалися в інтервалах MJD 58440-58494 i 58603-58654. Амплітуда змінності потоку була найбільша в рентгенівському діапазоні і зменшувалася зі збільшенням довжини хвилі. Спектри низької роздільної здатності (серпень 2018 г.) демонструють драматичне посилення широких компонентів емісійних ліній, а також ліній високої іонізації [FeX] (наприклад, $6374 \AA$ А). Ці лінії ніколи не спостерігалися такими інтенсивними в минулому в опублікованих спектрах. Зміна типу оптичного спектру супроводжувалася значною зміною рентгенівського спектра. За останніми оптичним спектрами (31 листопада 2018 р - 28 березня 2019 р.) ми бачимо драматичні зміни в порівнянні з 2 серпня 2018 р., які супроводжуються значним ослабленням широких емісійних ліній, а також лінії високої іонізації [FeX] 6374 А․ По суті, для цього об'єкта спостерігалися два випадки зміни типу (CL): перехід в тип Sy1.2, а потім повернення в низький стан 3 типом Sy 1.8 Sy1.9. Обговорюються деякі можливі пояснення спостережуваних драматичних змін.

Key words: Galsxies - active galaxies: individual: NGC 1566. 


\section{Introduction}

The NGC 1566 was discovered at 1826 by James Dunlop and has long history of investigations (see e.g. references at da Silva et al., 2017; Oknyansky et al., 2019; Parker et al., 2019). The broad nuclear emission lines characteristic of the Seyfert phenomenon in this object were discovered in 1956 (de Vaucouleurs G. \& de Vaucouleurs A., 1961; de Vaucouleurs, 1973) and confirmed in 1962 (Shobbrook, 1966). The NGC 1566 nucleus was later classified as type 1 . It is one of the brightest $\left(V \approx 10^{m} .0\right.$ but $V_{A G N} \approx 13^{m} .0$ in 5 arcsec radius aperture) and nearest galaxies with AGN in the South Hemisphere. This object is also nearest Changing Look (CL) AGN (Oknyansky et al., 2019). The nucleus of NGC 1566 has a low brightness relative to the host galaxy $\left(V \approx 13^{m} .0\right)$ and CL events there were probably discovered just because it is so close. The Changing Look active galactic nuclei (CL AGNs) are objects which undergo dramatic variability of the emission line profiles and classification type, which can change from type 1 (showing both broad and narrow lines) to type 1.9 (where the broad lines almost disappear) or vice versa within a short time interval (typically a few months). The dramatical spectral variations in NGC 1566 had been reported firstly by Pastoriza and Gerola (1970) after comparison of the spectrum obtained in 1969 with some of the earliest spectroscopic investigations, in 1956 (de Vaucouleurs G. \& de Vaucouleurs A., 1961), in 1962 (Shobbrook, 1966) where broad $\mathrm{H} \beta$ line was much more intensive. That was done soon after discovery of variability of AGNs in continuum (Fitch et al., 1967) and variability of emission lines was not too unexpectable. The object had several dramatic changes of its spectrum during the past tens of years (da Silva et al., 2017) but was not identified as a CL AGN until the 2018 event (Oknyansky et al., 2018; Oknyansky et al., 2019) since this designation only came into common use in the past decade.

NGC 1566 is a galaxy with a very well-studied variable active nucleus, but most intensive multiwave photometic observations were done during past year after discovery of a new reawakening (Kuin et al., 2018; Ferrigno et al., 2018; Grupe et al., 2018a; Parker et al., 2019; Cutri et al., 2018) and new CL phase (Oknyansky et al., 2018; Oknyansky et al., 2019 and references there). A substantial increase of X-ray flux by 1.5 orders of magnitude was observed following the brightening in the UV and optical bands during the last year. After a maximum was reached at the beginning of July 2018 the fluxes in all bands decreased with some fluctuations. The amplitude of the flux variability is strongest in the $\mathrm{X}$-ray band and decreases with increasing wavelength. Low resolution spectra (obtained near maximal level of state Oknyansky et al.
(2019)) reveal a dramatic strengthening of the broad emission as well as high ionisation $[\mathrm{FeX}] 6374 \AA$ lines. These lines were not detected so strongly in the past published spectra. The change in the type of the optical spectrum was accompanied by a significant change in the X-ray spectrum. All these facts give opportunity to classify NGC 1566 as CL (Oknyansky et al., 2018; Oknyansky et al., 2019). Following monitoring with Swift reveiled re-brightening of the object in December 2018 (Grupe et al., 2018b) and at the end of May 2019 (Grupe et al., 2019), however these outbursts were not so bright as in July 2018. Such re-brightenings after most dramatical outbursts probably are typical propety of the some part of CL AGNs since were noted in several other ones of them (Oknyansky et al., 2017; Oknyansky et al., 2018; Katebi et al., 2018).

\section{Observational data and results}

We summarize a study of optical, UV and X-ray light curves of the nearby changing look active galactic nucleus in the galaxy NGC 1566 obtained with the Neil Gehrels Swift Observatory and the MASTER Global Robotic Network over the period 2007-2019. The light curves for 2007-2018 are presented by Oknyansky et al. (2019) and those for the years 2018-2019 are shown in Fig. 1. It can be seen there that all variations in the optical, UV and X-ray are well correlated. We also report on optical spectroscopy using the South African Astronomical Observatory 1.9-m telescope between Aug 2018 (Oknyansky et al., 2018; Oknyansky et al., 2019) and Mar 2019. A substantial increase in X-ray flux by 1.5 orders of magnitude was observed following the brightening in the UV and optical bands during the first half of 2018 (Ducci et al., 2018; Kuin et al., 2018; Ferrigno et al., 2018; Grupe et al., 2018a; Oknyansky et al., 2018; Oknyansky et al., 2019; Parker et al., 2019). The amplitude of the flux variability is strongest in the $\mathrm{X}$-ray band and decreases with increasing wavelength. After a maximum was reached at the beginning of July 2018, the fluxes in all bands decreased with some fluctuations. The most remarkable re-brightening in the light curve following the decline from the bright phase was observed at MJD range 58440-58494 (Event 1) and 58603-58654 (Event 2). Event 1 and Event 2 are indicated in Fig. 1 (see also Grupe et al., 2018b; Grupe et al., 2019). The amplitudes of the re-brightening in UV and optical bands are significantly higher for Event 1 than for Event 2. That is different from the X-ray variations for which fluxes in the maxima were about the same. This difference is well seen at Fig. 1. If we take into account the host galaxy contamination in the aperture used then the relative decreases from the maximum in July 2018 to minimum in June 2019 in the different UV/Opt bands were about the same 


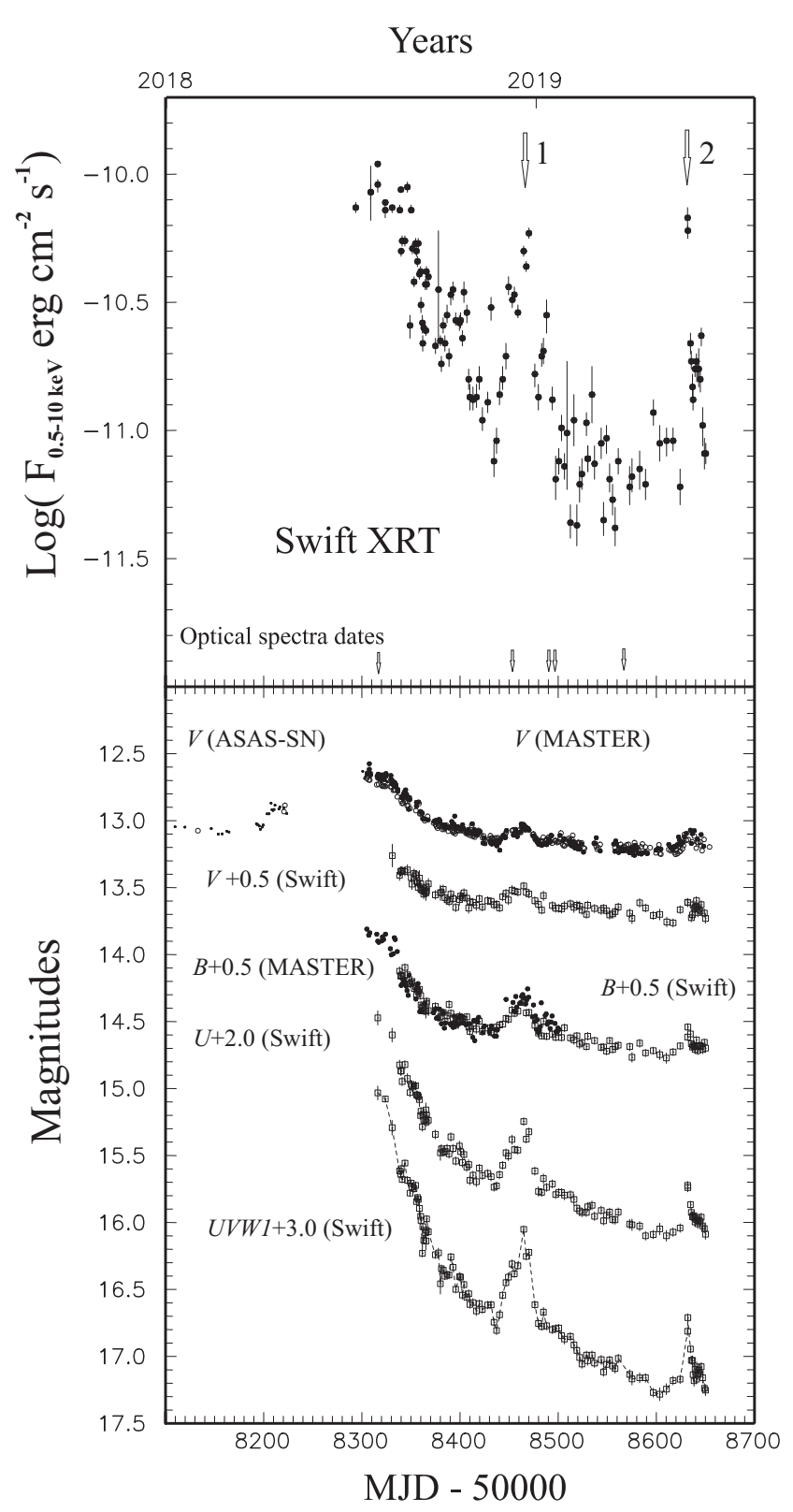

Figure 1: Multi-wavelength observations of NGC 1566 shown for 2018-2019 only. Top Panel: The Swift/XRT 0.5-10 keV X-ray flux (in erg $\mathrm{cm}^{-2} \mathrm{~s}^{-1}$ ) - (filled circles). Bottom Panel: The large open circles are MASTER unfiltered optical photometry of NGC 1566 reduced to the $V$ system while the points are $V$ ASAS-SN (nightly means) reduced to the Swift $V$ system. The filed circles are MASTER $B V$ photometry. The open boxes are $U V W 1$ and $U B V$ data obtained by Swift.

\section{( $\sim 9$ times).}

Low-resolution spectra (2 Aug 2018) (see Fig. 2) reveal a dramatic strengthening of the broad emission as well as high-ionization [FeX]6374Å lines. These lines were not detected so strongly in the past published spectra. The change in the type of the optical spectrum (Oknyansky et al., 2018; Oknyansky et al.,
2019) was accompanied by a significant change in the X-ray spectrum. For the last spectra (30 Nov 2018 28 Mar 2019) we see dramatic changes compared to Aug 2018, accompanied by the fading of the broad emission lines. Effectively, two changing look cases were observed by us for this object during the past year.

\section{Conclusion}

NGC 1566 is one of the typical examples of a CL AGN, since it demonstrates dramatical variability of broad emission lines, UV continuum, high ionisation lines like [FeVII] and [FeX], and also recurrent brightening and dimming events. NGC 1566 is one of the clearest illustrations of Seyfert spectra ranging from type 1.2 to type 1.9 AGNs at different epochs. The object is nearest AGN and CL AGN and so it offers one of the best opportunities for studying this phenomenon. The light curves from X-ray to optical bands presented here show very good correlations over a long time interval. This result is mostly in agreement with a scenario where the variability across several wavebands (spanning X-rays-UV/Optical) is driven by variable illumination of the accretion disc by soft X-rays (see the same conclusions for another CL object, NGC2617 (Shappee et al., 2014; Oknyansky et al., 2017)). We have shown, using spectroscopy (1.9 m SAAO) and multi-wavelength photometry (MASTER, Swift Ultraviolet/Optical and XRT Telescopes), that NGC 1566 recently experienced a dramatic outburst in all wavelengths, including a considerable strengthening of broad permitted and high ionisation $[\mathrm{FeX}] 6374 \AA$ lines, as well as substantial changes in the shape of the optical and X-ray continua (Oknyansky et al., 2019). After a maximum was reached at the beginning of July 2018, the fluxes in all bands dramatically decreased with some fluctuations. The strength of the broad permitted, high ionisation [FeX]6374Ålines and UV continuum dramatically decreased (end of March 2019) and the object can then be classified as Sy1.8Sy1.9. So we witnessed a second CL case in NGC1566.

Despite the successes of the simple orientation-based AGN unification scheme, there are significant problems that cannot be explained solely by different orientations. A major challenge to the simple model is the existence of CL AGNs. Orientation obviously cannot change on the time-scale of the observed type changes, and hence some other explanation is needed. What must happen to make such a dramatic changes possible? An alternative explanation is that transitions from type 1 to type Sy2 AGNs or vice versa are connected with some dramatic variability of the ionizing radiation, such as temporarily switching on or switching off their engine (Lyuty et al., 1984; Penston et al., 1984; Runnoe et al., 2016; Katebi et al., 2019). More references on the possible explanations for the CL phe- 


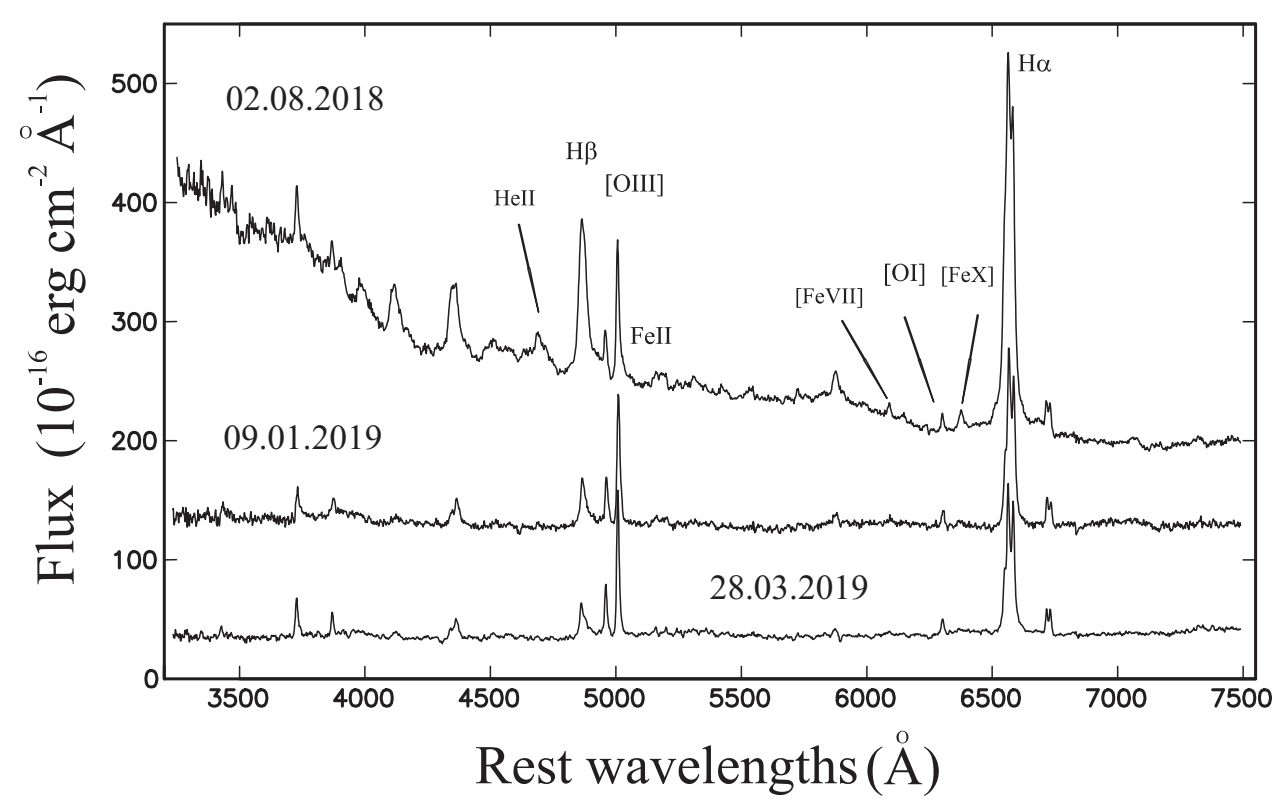

Figure 2: The isolated nuclear (low resolution) nonstellar spectra (solid line) in NGC 1566 obtained by subtraction of the host galaxy spectrum (thin line) from the original spectrum. (See details in the text). The spectra for 2 Aug 2018 and 9 Jan 2019 are shifted up $10^{-14} \mathrm{ergcm}^{-2} A^{-1}$ for good seeing

nomenon can be found in discussions by MacLeod et al. (2019) and Ruan et al. (2019).

Acknowledgements. HW and FVW thank the South African Astronomical Observatory for the generous allocation of telescope time which also resulted in the spectra presented in this paper. We also express our thanks to the Swift ToO team for organizing and executing the observations. This work was supported in part by the Russian Foundation for Basic Research through grant 17-52-80139 BRICS-a and by the BRICS Multilateral Joint Science and Technology Research Collaboration grant 110480. MASTER work was supported by Lomonosov Moscow State University Development Programme and RSF grant 16-12-00085. DB is supported by the National Research Foundation of South Africa. We are grateful to K. Malanchev and P. Ivanov for useful discussions.

\section{References}

Cutri R.M., Mainzer A.K., Dyk S.D.V. et al.: 2018, The Astronomer's Telegram, 11913.

da Silva P., Steiner J. E. and Menezes R.B.: 2017, MNRAS, 470, 3850 .

de Vaucouleurs G. and de Vaucouleurs A.: 1961, MNRAS, 68, 69.

de Vaucouleurs G.: 1973, ApJ, 181, 31.

Ferrigno C., Siegert T., Sanchez-Fernandez C. et al.: 2018, The Astronomer's Telegram, 11783.

Fitch W.S., Pacholczyk A.G. and Weymann R.J.: 1967, ApJ, 150, L67.

Grupe D., Komossa S. and Schartel N.: 2018a, The Astronomer's Telegram, 11903.
Grupe D., Mikula R., Komossa S. et al.: 2018b, The Astronomer's Telegram, 12314.

Grupe D., Mikula R., Komossa S. et al.: 2019, The Astronomer's Telegram, 12826, 1.

Katebi R., Chornock R., Berger E. et al.: 2018, arXiv e-prints [1811.03694].

Katebi R., Chornock R., Berger E. et al.: 2019, MNRAS, 487, 4057.

Kuin P., Bozzo E., Ferrigno C. et al.: 2018, The Astronomer's Telegram, $\mathbf{1 1 7 8 6 .}$

Lyutyj V.M., Oknyanskij V.L. and Chuvaev K.K.: 1984, Sov. Astron. Lett., 10, 335.

MacLeod C.L., Green P.J., Anderson S.F. et al.: 2019, ApJ, 8748.

Oknyansky V.L., Gaskell C.M., Huseynov N.A. et al.: 2017, MNRAS, 467, 1496.

Oknyansky V.L., Lipunov V.M., Gorbovskoy E.S. et al.: 2018, The Astronomer's Telegram, 11915.

Oknyansky V.L., Winkler H., Tsygankov S.S. et al.: 2019, MNRAS, 483, 558.

Parker M.L., Schartel N., Grupe D. et al.: 2019, MNRAS, 483, L88.

Pastoriza M. and Gerola H.: 1970, Astrophys. Lett., 6. 155.

Penston M.V. and Perez E.: 1984, MNRAS, 211, 33.

Ruan J.J., Anderson S.F., Eracleous M. et al.: 2019, arXiv e-prints arXiv:1909.04676 [1909.04676].

Runnoe J.C., Cales S., Ruan J.J. et al.: 2016, MNRAS, 455, 1691.

Shappee B. J., Prieto J. L., Grupe D. et al.: 2014, ApJ, 788, 48.

Shobbrook R.R.: 1966, MNRAS, 131, 365. 